\title{
SOCIALISMO E DEMOCRACIA NO MARXISMO DE CARLOS NELSON COUTINHO (1943-2012)
}

Marco Aurélio Nogueira

Quando publicou, em março de 1979, na revista Encontros com a Civilização Brasileira, o ensaio "A democracia como valor universal”, Carlos Nelson Coutinho já era um autor de destaque no Brasil. Marxista de base lukacsiana, havia escrito dois belos e importantes livros - Literatura e humanismo, de 1967, reunião de artigos de estética e crítica literária, e $O$ estruturalismo e a miséria da razão, de 1972, em que submetia à crítica as ideias positivistas que se insinuavam entre a intelectualidade e no próprio campo marxista. Havia também elaborado vários artigos sobre cultura brasileira, filosofia e teoria política. Ainda jovem, era um autor prolífico, que se singularizava pelo texto límpido, rigoroso e erudito.

Mas foi com esse ensaio (Coutinho, 1980) sobre a democracia que Carlos Nelson ingressou de vez na cena política e intelectual brasileira, para dela nunca mais sair. Poucos textos tiveram tanta influência quanto aquele. Em plena ditadura militar no Brasil, o ensaio lançava uma luz na escuridão; era como uma golfada de ar num ambiente reprimido e sufocado, num momento em que as esquerdas (dentro e fora do país) ainda digeriam o 
radicalismo pouco consequente das "guerrilhas" e, sem conseguir assimilar a nova fase do capitalismo, as novas formas sociais e a dimensão revolucionária da democracia política, se envolviam em polêmicas verborrágicas sobre o caráter "burguês" ou "proletário" da democracia e sobre o "melhor caminho para o socialismo". Dizia com todas as letras, logo nas primeiras linhas:

A questão do vínculo entre socialismo e democracia marcou sempre, desde o início, o processo de formação do pensamento marxista; e, direta ou indiretamente, esteve na raiz das inúmeras controvérsias que assinalaram e assinalam a história da evolução desse pensamento (Coutinho, 1980, p.19).

Tratava-se de um vínculo constitutivo do pensamento de Marx e dos grandes marxistas, que não podia, portanto, 12 ser abandonado ou menosprezado. Ao contrário, precisava ser plenamente recuperado, valorizado e atualizado. Era hora de romper o marasmo, eliminar os vetos "marxistas-leninistas" à democracia política "burguesa" e conceber uma estratégia democrática de transformação social, superando as limitações das prevalecentes teorias marxistas do Estado, da revolução e do partido. Naquela altura da história das lutas sociais no mundo, não fazia mais sentido menosprezar os procedimentos formais de representação, decisão e criação de vontade política, que surgiram no curso das revoluções burguesas clássicas e adquiriram dimensão de "valor universal", ou seja, ganharam validade geral e se incorporaram à experiência concreta das sociedades modernas, enriquecendo o gênero humano. O texto era claro:

As objetivações da democracia - que aparecem como respostas, em determinado nível histórico-concreto 
da socialização do trabalho, ao desenvolvimento correspondente dos carecimentos de socialização da participação política - tornam-se valor na medida em que contribuíram, e continuam a contribuir, para explicitar as componentes essenciais contidas no ser genérico do homem social. E tornam-se valor universal na medida em que são capazes de promover essa explicitação em formações econômico-sociais diferentes, ou seja, tanto no capitalismo quanto no socialismo (Coutinho, 1980, p.24).

A argumentação vinha apoiada em um consistente arcabouço filosófico e valia-se do estímulo provocado por uma instigante declaração de Enrico Berlinguer, então secretário-geral do Partido Comunista Italiano (PCI), que afirmara, nas comemorações do $60^{\circ}$. aniversário da Revolução de 1917: "A democracia é hoje não apenas o terreno no qual o adversário de classe é obrigado a retroceder, mas é também o valor historicamente universal sobre o qual fundar uma original sociedade socialista" (apud Radice, 1979, p.128). A sofisticada teoria política do PCI, então no auge de sua forma física e intelectual, constituía naqueles anos a principal referência do marxismo que desejasse ser criação crítica e não somente repetição de formulações consagradas. Ela irá ressoar com força no texto de Carlos Nelson e repercutirá intensamente nos ambientes democráticos $\mathrm{e}$ de esquerda no Brasil. A aceitação plena do pluralismo, da busca de consensos, da multiplicidade de sujeitos políticos, da alternância de poder e da institucionalidade democrática tout court era então posta no centro da reflexão política, num movimento teórico que deixava patente a adesão de Carlos Nelson à perspectiva gramsciana da luta por hegemonia, tema que ele iria desenvolver mais tarde em seu excepcional livro Gramsci, de 1999.

Uma revolução poderia certamente ocorrer, mas ela não seria "explosiva" e sim processual, encadearia reformas 
ao longo de um tempo impossível de determinar em abstrato. O Estado permaneceria como "aparelho" de opressão de classe, mas alteraria sua forma em decorrência das pressões sociais, da socialização política e da complexificação da estrutura social no capitalismo mais avançado, acentuando sua condição de arena privilegiada da luta de classes. Portanto, também tinha de ser compreendido pela chave ético-política que Gramsci aproveitara de Benedetto Croce: um agente de educação, espaço indissociável da sociedade civil, locus de negociação e de construção de consensos, uma instância de governo e direção política. Tratava-se de assimilar a ideia do Estado ampliado, um compósito de força e consenso, coerção e hegemonia, instituições, valores e massas organizadas.

Eventuais governos socialistas não poderiam abrir mão desses elementos, sob pena de não se completarem como promessa reformadora. Se outro Estado pudesse ser conce14 bido (e Carlos Nelson estava seguro de que podia), ele se assentaria nessa dimensão universal da vida política e social moderna. Uma nova hegemonia - capacidade de direção política de um sujeito coletivo - somente poderia fazer sentido e ter desdobramento prático progressista se partisse do reconhecimento da pluralidade irredutível dos sujeitos e da irrevogabilidade das contradições sociais, ou seja, se saísse do campo nebuloso dos "princípios" e se colasse à vida, à complexidade real, aos tempos históricos particulares. A condição de possibilidade dessa nova hegemonia estava dada pela incorporação sem subterfúgios da perspectiva democrática.

Para Carlos Nelson, a democracia precisava ser tratada como valor universal porque era um valor em si e uma construção histórica que se fixara no horizonte da modernidade, abrindo-se assim, não como "caminho" ou "instrumento", mas como plataforma de estruturação e impulsionamento de todos os movimentos políticos progressistas, 
reformadores. Ela não era somente base de um novo contrato social e um conjunto de "regras do jogo", mas também uma pedagogia para a luta e para a transformação social. Ensinaria aos homens o valor dos "outros", a dignidade das pessoas, a tolerância, a relevância do diálogo, a complexidade da política e do político - fatores que se revestem de um extraordinário poder de contestação e de agregação cívica.

A essa postulação, Carlos Nelson reunia uma teoria da sociedade e uma estratégia política, o que fazia de sua argumentação uma análise concreta de situações concretas. Aceitar a democracia como valor universal não era um repto teórico ou filosófico, muito menos uma "tática política" ou uma provocação que se fazia a uma esquerda fraseológica que parara no tempo, mas tratava-se antes de tudo do desdobramento lógico de uma visão da realidade histórico-social, de uma compreensão do capitalismo contemporâneo e de seus desafios em escala nacional e internacional.

Particularmente no caso do Brasil - país que havia sido condicionado por um padrão selvagem e autoritário de desenvolvimento capitalista -, a questão democrática estava no centro de tudo. Em 1979, em meio aos anos de chumbo, às vésperas da anistia política e do início do último período da ditadura militar, o tema adquiria peso decisivo. Saber resolvê-lo teoricamente era qualificar uma teoria da ação, estruturar uma agenda de lutas e dar sustentação a um discurso que precisava ganhar as multidões. Era também um modo de conceber o Estado e suas políticas, a relação governantes/governados, as reformas sociais e a fixação da cidadania. A democratização que já se anunciava no plano social e cultural precisava ser estendida ao plano político imediato. $\mathrm{O}$ mesmo raciocínio poderia incluir os distintos países da América Latina, ainda que com ritmos e cores particulares.

Não foi, portanto, por acaso ou por mero capricho teórico que o ensaio de Carlos Nelson incorporou de for- 
ma inovadora e criativa o conceito leniniano de "via prussiana", valendo-se para tanto do tratamento mais ampliado que Georg Lukács lhe dera. Segundo o filósofo húngaro, o conceito não deveria se limitar ao modo como a questão agrária seria resolvida em sentido estrito (como a propriedade da terra seria incorporada aos padrões capitalistas), mas envolver todo o desenvolvimento do capitalismo e a superestrutura política das sociedades burguesas. Lukács também aproximou esse conceito dos problemas da cultura e da intelectualidade, ao dar operacionalidade à ideia de "intimismo à sombra do poder", com o que destacava o imenso poder de atração exercido sobre os intelectuais pelos núcleos do poder de Estado, principal "agente" de modernização. A falta de democracia e de participação popular seriam subprodutos inevitáveis desse padrão de revolução burguesa, no qual a modernização faz concessões para poder avançar e é por isso "conservadora", ten16 dendo para o encontro de soluções autoritárias. Assim teria ocorrido na Alemanha (nazismo) e na Itália (fascismo) (Lukács, 1972, pp.29-74).

Ciente de que não se tratava de simplesmente "aplicar" o conceito como se fosse um modelo, mas sim de tomá-lo como referência macro, Carlos Nelson o utilizou para construir sua análise da situação brasileira, cuja revolução burguesa assumiu caráter abertamente antidemocrático. As transformações políticas e a modernização capitalista ocorridas no Brasil não resultaram de autênticas revoluções, de movimentos provenientes de baixo para cima, que envolveriam o conjunto da população, mas sempre foram efetuadas de forma "prussiana", ou seja,

[...] através da conciliação entre frações das classes dominantes, de medidas aplicadas de cima para baixo, com a conservação de traços essenciais das relações de produção atrasadas (o latifúndio) e com a reprodução 
ampliada da dependência ao capitalismo internacional (Coutinho, 1980, p.32).

Nessa dinâmica, as classes e camadas sociais "de baixo" permaneceram marginalizadas, reprimidas e fora do âmbito das grandes decisões políticas.

A transição brasileira para o capitalismo (e de cada fase do capitalismo para a fase subsequente) deu-se tanto no quadro da reprodução ampliada da dependência - ou seja, com a passagem da subordinação formal à subordinação real em face do capital mundial - quanto no quadro de uma "modernização conservadora": relações de produção atrasadas (o latifúndio) foram preservadas e incorporadas funcionalmente ao capitalismo. Tal fator pesou como uma bola de chumbo sobre toda a história nacional, retardando dramaticamente uma industrialização centrada no mercado interno ampliado e facilitando a monopolização precoce e a dependência externa.

O combate ao autoritário elitismo "prussiano" confundia-se, assim, com a renovação democrática da vida social, que se mostrava o modo mais avançado de levar a cabo as tarefas que a ausência de uma revolução democrático-burguesa deixara em aberto. A democracia adquirira valor universal e potência subversiva.

No ensaio de 1979, o conceito leninista e lukacsiano de "via prussiana" era incorporado de forma reflexiva e não como modelo a ser aplicado. Carlos Nelson, já então, apropriara-se dos conceitos de "revolução passiva", "revolução-restauração" e "revolução pelo alto", com os quais Gramsci não só acentuara o caráter antidemocrático e conservador do desenvolvimento capitalista italiano, como também procurara compreender a dinâmica do capitalismo que se encaminhava para o fascismo e para o Estado de bem-estar (Gramsci, 1999-2002, passim). A "revolução passiva” gramsciana era assim usada como "critério de interpretação" da 
formação social brasileira, na qual podiam ser visualizados os mesmos fenômenos observados por Gramsci na Itália: fortalecimento do Estado em detrimento da sociedade civil, com o predomínio das formas ditatoriais da supremacia em detrimento das formas hegemônicas, e a prática do transformismo como modalidade de desenvolvimento histórico que implica a exclusão das massas. Dali em diante, ainda que modificasse e corrigisse suas formulações, Carlos Nelson não mais se afastaria desse modo de pensar.

A teorização traduzia-se em estratégia política: as lutas populares - e mais concretamente a luta contra a ditadura militar no Brasil - teriam de avançar por uma estrada longa e árdua, ganhando oxigênio ao se unificarem em torno da luta pelas liberdades democráticas e pela democracia política. A opção pelo que Gramsci chamara de "guerra de posição" era assim uma imposição da realidade: a recusa ao "golpismo de esquerda" (que será visto por Carlos Nel-

18 son como atravessado por um tipo semelhante de elitismo "prussiano") e a progressiva obtenção de posições firmes na sociedade civil tornariam possível a conquista democrática do poder de Estado pelas forças progressistas. A renovação democrática, a democratização, seria o conteúdo estratégico da revolução socialista no Brasil e na América Latina, poder-se-ia dizer.

Os anos de 1980, período em que a ditadura brasileira se decompõe acossada por um movimento democrático de amplas bases populares, dariam razão a essa perspectiva. Nas décadas seguintes, com Fernando Henrique Cardoso (1995-2002) e Luiz Inácio Lula da Silva (2003-2010), o Brasil avançaria política e socialmente, ainda que com altos e baixos, mediante a consolidação da democracia política.

Em paralelo à consolidação de sua matriz teórica, Carlos Nelson iria atualizá-la e aprofundá-la. Reformularia algumas ênfases, incorporaria de modo pleno a perspectiva gramsciana da "revolução passiva", voltaria a dialogar 
com Lukács, (Coutinho, 2005a), traria Rousseau para o debate marxista (Coutinho, 2011) e manteria incansável trabalho de reflexão sobre cultura brasileira (Coutinho, 1986, 2005b) e, em particular, sobre marxismo (Coutinho, 1992, 1994, 2006). Em todas suas intervenções, permaneceriam vivas as apostas teóricas e políticas feitas no famoso texto de 1979.

Carlos Nelson escreveu esse ensaio seminal como militante do Partido Comunista Brasileiro (PCB), do qual se afastou nos primeiros anos da década de 1980. Mais tarde, em 1989, ingressou no Partido dos Trabalhadores. Em 1986, tornou-se professor da Escola de Serviço Social da Universidade Federal do Rio de Janeiro, que lhe concedeu o título de professor emérito em junho de 2012.

Foi nessa condição de intelectual militante que concebeu e coordenou a edição brasileira de Cadernos do Cárcere de Antonio Gramsci, publicado pela Civilização Brasileira entre 1999 e 2002 em seis volumes. Envolveu-se em muitas conversas, discussões e sessões de estudo para estruturar a obra. O planejamento foi rigoroso e minucioso. Supervisionou todo o trabalho, traduziu, redigiu notas complementares e introduções, com a colaboração decisiva de Luiz Sérgio Henriques, editor da revista eletrônica Gramsci e o Brasil ${ }^{1}$. Carlos Nelson a chamava de "edição temática dos Cadernos", para realçar a perspectiva então seguida de privilegiar as notas finalizadas e organizadas (segundo determinados temas) por Gramsci. Não a via como uma edição crítica ou completa, para especialistas, mas como uma edição destinada a fazer com que Gramsci fosse melhor conhecido e estudado no Brasil. Esta foi sua maior realização.

Ao longo dos governos Lula da Silva, Carlos Nelson divergiu seguidamente das opções e das políticas governamentais então adotadas. Entendeu que elas não favo-

\footnotetext{
${ }^{1}$ Disponível na página eletrônica www.gramsci.org.
} 
reciam mudanças econômicas e sociais mais profundas. Não aceitava que Lula se autoproclamasse um político que jamais havia sido de esquerda, nem muito menos o modo como o PT era dirigido e atuava, com excessivas preocupações eleitorais e muitas conciliações. Em 2004, trocou o PT pelo Partido Socialismo e Liberdade (Psol), uma pequena agremiação composta por diversas tendências e dissidências de esquerda que haviam discordado do PT durante os primeiros anos da presidência Lula. Fez seu périplo partidário sem se afastar da visão democrática, do compromisso socialista, da paixão intelectual por Gramsci e pela batalha de ideias. Foi até o fim um comunista democrático, generosamente aberto ao diálogo, à controvérsia e à reforma social.

A morte de Carlos Nelson em setembro de 2012 deixou a cultura e as esquerdas brasileiras mais pobres e vazias; seu trabalho, porém, deixou para elas um legado intelectual rico 20 e substantivo. Para os que puderam com ele conviver, discutir, trabalhar e fazer política, para os que leram e aprenderam com seus textos, a sensação é de perda, mas também de serena compreensão de que Carlos Nelson cumpriu uma função de extraordinária importância no desenvolvimento do pensamento democrático e socialista no Brasil.

\section{Marco Aurélio Nogueira}

é cientista político, diretor do Instituto de Políticas Públicas e Relações Internacionais da Unesp.

\section{Referências Bibliográficas}

COUTINHO, C. N. 1967. Literatura e humanismo: ensaios de crítica marxista. Rio de Janeiro: Paz e Terra. 1972. O estruturalismo e a miséria da razão. Rio de Janeiro: Paz e Terra. 1980. A democracia como valor universal: notas sobre a questão democrática no Brasil. São Paulo: Livraria Editora Ciências Humanas. 1986. Literatura e ideología en Brasil: tres ensayos de crítica marxista.

Havana: Casa de Las Américas. 
1992. Democracia e socialismo: questões de princípio e contexto brasileiro. São Paulo: Cortez. 1994. Marxismo e política: a dualidade de poderes e outros ensaios. São Paulo: Cortez.

1999. Gramsci: um estudo sobre seu pensamento político. Rio de Janeiro: Civilização Brasileira.

2005a. Lukács, Proust e Kafka: literatura e sociedade no século XX. Rio de Janeiro: Civilização Brasileira.

2005b. Cultura e sociedade no Brasil: ensaios sobre ideias e formas. Rio de Janeiro: DP\&A.

2006. Intervenções: o marxismo na batalha das ideias. São Paulo: Cortez. 2011. De Rousseau a Gramsci: ensaios de teoria política. São Paulo: Boitempo.

GRAMSCI, A. 1999-2002. Cadernos do cárcere. Rio de Janeiro: Civilização Brasileira, 6 vols.

LUKÁCS, G. 1972. El Asalto a la razón: la trayectoria del irracionalismo desde Schelling hasta Hitler. Barcelona-México: Ediciones Grijalbo.

RADICE, L.L. 1979. Un socialismo da inventare. Roma: Riuniti. 